\title{
Pilot Study of the Malay Maslach Burnout Inventory and Malay Work-Related Quality of Life Scale in Malaysia
}

\author{
Won-Sun Chen ${ }^{1}$, Jamaiyah Haniff ${ }^{2}$, Ching-Sin Siau ${ }^{3}$, Wymen Seet ${ }^{2}$, Sit-Fong Loh $^{4} \&$ Mohd Hadzrul Abd Jamil ${ }^{5}$ \\ ${ }^{1}$ School of Science, Monash University Malaysia, Selangor, Malaysia \\ ${ }^{2}$ National Clinical Research Centre, Ministry of Health, Kuala Lumpur, Malaysia \\ ${ }^{3}$ American Degree Program, SEGi University, Selangor, Malaysia \\ ${ }^{4}$ Turning Point Integrated Wellness Sdn Bhd, Selangor, Malaysia \\ ${ }^{5}$ Research \& Innovation Management Centre, SEGi University, Selangor, Malaysia \\ Correspondence: Won-Sun Chen, School of Science, Monash University Malaysia, Jalan Lagoon Selatan, 46150 \\ Bandar Sunway, Selangor, Malaysia. Tel: 603-5514-6106. E-mail: chen.won.sun@monash.edu
}

Received: November 9, 2013 Accepted: November 20, 2013 Online Published: November 21, 2013

doi:10.5430/sass.v1n1p20 URL: http://dx.doi.org/10.5430/sass.v1n1p20

\begin{abstract}
It was important to establish a reliable Malay Maslach Burnout Inventory (MBI) and Malay work related quality of life scale (WRQoL) to address the issue of burnout and work related quality of life in Malaysia. Specifically, the MBI instrument encompassed Maslach Burnout Inventory - Health Services Survey (MBI-HSS), Maslach Burnout Inventory - General Services (MBI-GS), Maslach Burnout Inventory - Educators Surveys (MBI-ES). The English versions of MBI and WRQoL instruments were translated into Malay based on forward and backward translation methods. A pilot study was conducted to assess the properties of these translated instruments.

A weighted kappa was used to measure the strength of agreement between the English and Malay instruments, while Cronbach's alpha was used to assess the internal reliability of the translated instruments.

Weighted kappa revealed moderate to almost perfect strength of agreement between the English and Malay versions of instruments. The overall Cronbach's alpha of at least 0.90 clearly indicated items in the translated instruments measured the same concept or construct.

This study demonstrated the properties of Malay versions of the MBI-HSS, MBI-GS, MBI-ES and WRQoL instruments were culturally appropriate and acceptable to be used in Malaysia.
\end{abstract}

Keywords: Maslach Burnout Inventory, Work-Related Quality of Life Scale, Malaysia, Translation, Reliability

\section{Introduction}

The concept of "burnout" was first introduced in the 1970s and it was defined as a feeling of failure and being worn out (Freudenberger, 1974). Another definition of burnout was a progressive loss of idealism, energy and purpose (Edelwich \& Brodsky, 1980). This concept was further defined as a state of physical, emotional and mental exhaustion (Pines \& Aronson, 1981), or a coping mechanism to working conditions that are stressful, demanding and lack of recognition (Sarros \& Densten, 1989). As the stress continues, one may begin to lose interest or motivation in life. Effects of burnout include low productivity, feeling increasingly hopeless, powerless, cynical and resentful, which can eventually threaten one's job satisfaction, relationship and also health (4-Life Psychology Centre, 2012).

It was crucial for organizations to realize working environment could potentially be a contributor to mental ill health and also the well-being of an employee. This was mainly because mental ill health has been reported as the second highest work related illness after musculoskeletal disorder (Glozier, 2002). Interestingly, burnout was not a recognized disorder in the Diagnostic and Statistical Manual of Mental Disorders (DSM-IV-TR), which was a common language and standard criteria for the classification of mental disorders published by the American Psychiatric Association (Kraft, 2006). On the other hand, burnout was a recognized disorder in the International Statistical Classification of Diseases and Related Health Problems (ICD-10), which was a coding of diseases and signs, symptoms, abnormal findings, complaints, social circumstances and external causes of injury or diseases, as 
classified by the World Health Organization (WHO) (World Health Organization [WHO], 1994).

\subsection{Maslach Burnout Inventory (MBI)}

The Maslach Burnout Inventory (MBI) has been recognized as the leading measure of burnout with more than 25 years of extensive research since its initial publication. This measure generally addressed three subscales, namely 1) emotional exhaustion which measures feelings of being emotionally overextended and exhausted due to work, 2) depersonalization which measures the unfeeling and impersonal response towards one's service and care treatment, and 3) personal accomplishment which measures one's successful achievement and competency at work. This instrument has further been categorized specifically to measure the perception of three defined groups on their job as well as the people whom they closely interact with. These instruments were known as MBI - Human Services Survey (HSS), MBI - Educators Survey (ES), and MBI - General Survey (GS). The items were scored on a seven-point Likert scale from 0 (never) to 6 (everyday) (Leiter \& Maslach, 2005a; Leiter \& Maslach, 2005b; Maslach \& 1997; Maslach, 2003; Maslach \& Leiter, 2008; Maslach, Leiter \& Schaufeli, 2009).

\subsubsection{MBI-HSS}

MBI-HSS was established to measure burnout as an occupational issue for people with direct contact with service recipients. Human services professionals ought to spend considerable amount of time with others. The so-called staff-client interaction mostly trying to resolve client's psychological, social or physical problem. Staff who continuously dealing with client's anger, frustrating or embarrassing emotions were draining, which can eventually lead to burnout. MBI-HSS contained 22 items forming 3 subscales, namely emotional exhaustion, personal accomplishment and depersonalization. Emotional exhaustion subscale assesses feeling of being emotionally exhausted due to work, while feeling of successful achievement in work was assessed by the personal accomplishment subscale. Depersonalization was a combination of physical and emotional thoughts which lead you feel disengaged from one's care or instruction (Maslach, Jackson \& Leiter, 1996).

\subsubsection{MBI-ES}

MBI-ES was developed mainly to identify burnout levels of individuals who work in schools environment. Similar to MBI-HSS, this instrument has 22 items from 3 subscales, namely emotional exhaustion, personal accomplishment and depersonalization. Emotional exhaustion referred to development of fatigue feeling as a result of overextended emotional energies, while personal accomplishment assessed educator's achievements in contributing to students' development. Depersonalization happened when educators experienced negative feelings about their students (Maslach et al., 1996).

\subsubsection{MBI-GS}

MBI-GS measured burnout from the perspective of one's performance at work in general. It comprised only 16 items from 3 subscales, namely professional efficacy, exhaustion and cynicism. Professional efficacy encompassed satisfactions and occupational accomplishments from both social and nonsocial aspects. The exhaustion subscale referred to fatigue from all aspects without any emphasis on emotions like in MBI-HSS. Cynicism was a reflection of distance attitude towards work due to coping with exhausting demands (Maslach et al., 1996).

\subsection{Work-Related Quality of Life (WRQoL) Scale}

The Work-Related Quality of Life (WRQoL) Scale was first established by a group of psychologists at the University of Portsmouth, who eventually formed a company called Quality of Working Life (QoWL) to make this tool available for future studies. This tool has further been enhanced after years of research incorporating feedback from more than 15,000 public sector employees. The WRQoL consisted of 24 items evaluated on a 5 point Likert scale from 6 subscales, namely general well-being, home-work interface, job-career satisfaction, control at work, working conditions and stress at work, which most relevant to quality of working life (Quality of Working Life [QoWL], 2012).

\subsubsection{General Well-being}

General well-being subscale assessed the well-being an individual from the perspective of overall life satisfaction and mental health problem such as depression and anxiety (Easton \& Van Laar, 2012).

\subsubsection{Home-work Interface}

The interrelationship between home and work life was reflected in home-work interface subscale. This subscale provided the extent to which the employer was perceived to support work and home life balance for employees (Easton \& Van Laar, 2012). 


\subsubsection{Job-career Satisfaction}

Job-career satisfaction subscale assessed the satisfaction level of employees towards their job as well as career enhancement and development (Easton \& Van Laar, 2012).

\subsubsection{Control at Work}

It was important for employee to be involved in decisions that affect their work. Control at work was simply a reflection of confidence level that employees have towards their job (Easton \& Van Laar, 2012).

\subsubsection{Working Conditions}

Working conditions assessed the fundamental resources and working environment provided to employees for them to perform their job safely and effectively (Easton \& Van Laar, 2012).

\subsubsection{Stress at Work}

This subscale measured the perception of employees that they encountered excessive pressure and felt stress at work (Easton \& Van Laar, 2012).

\subsection{Research Purpose and Objectives}

Although majority of the commonly used questionnaires were initially developed in English language, it was possible to translate these questionnaires into another language. One should not automatically assume that the validity and reliability of the items that were translated from one questionnaire to another remain intact. It was important to ensure the correct psychometric properties, such as validity and reliability, were incorporated in the translated instruments (Chen, 2009).

It was documented that a well translated instrument should possess semantic equivalence across languages, conceptual equivalence across cultures, and normative equivalence to the source survey. Semantic equivalence referred to the same meaning and sentence structure to be expressed and contained in the translated instrument compared to the original instrument. This was very similar to content validity, which was defined as the reflection of the specific intended domain of content in the translated instrument compared to the original instrument (Chen, 2009). Conceptual equivalence studied the same concept in the instrument regardless of wording used in different languages. Analogously, this was similar to construct validity which studied the agreement between a theoretical concept and a specific measuring procedure (Chen, 2009). Normative equivalence described the ability of the wording used in the translated instrument to address the cultural difference in social norms. For example, some populations were very conservative and were less expressive with regards to issues such as sexual, religion and health (Behling \& Law, 2000; Center for Aging in Diverse Communities. 2010). It was relatively easy and straightforward to achieve semantic and conceptual equivalence across languages because the words and ideas used were generally about the same. However, it was rather difficult to achieve normative equivalence due to cultural differences across continents. Therefore, it was very hard to achieve all types of equivalence when translating instrument (Behling \& Law, 2000).

In order to address the issue of "burnout" in Malaysia, it was very important to ensure that a reliable translated instrument was available locally and culturally acceptable. Therefore, this paper aimed at documenting the details of the translation process and establishing the reliability of the translated instruments based on pilot study.

\section{Method}

\subsection{Research Approach}

A cross sectional survey design was used to gather primary data by using the Malay versions of MBI-HSS, MBI-ES, MBI-GS and WRQoL instruments.

\subsection{Translation Process}

Permission was obtained from Mind Garden, Inc. and Quality of Working Life respectively to translate and use MBI and WRQoL scale for this study. Two independent professional bilingual translators from the National Translation Institute were hired to translate the original English versions of MBI-HSS, MBI-ES, MBI-GS and WRQoL into Malay. This was known as the forward translation. Similarly, another two independent bilingual translators were hired to back translate the harmonized Malay versions of MBI-HSS, MBI-ES, MBI-GS and WRQoL into English. This process was known as backward translation. Apart from the professional translators, both forward and backward translations were also conducted by a group of medical experts. A harmonization meeting involving the translators, medical experts and a multi-disciplinary researcher team was held to review, reconcile and harmonize the translated instruments (Chen, 2009). 


\subsection{Pilot Study of the Translated Instruments}

A pilot study was conducted by recruiting participants from hospitals and institutions located in the Klang Valley area during the month of November 2012. Three focus groups, with 10 participants for MBI-HSS and WRQoL, 10 for MBI-ES and WRQoL, and 10 for MBI-GS and WRQoL, were recruited to participate in this study. These participants were working adults with bilingual capability, and they were selected through convenience sampling. After informed consent was obtained verbally, participants in each focus group were given two sets of questionnaire (MBI-HSS and WRQoL, MBI-GS and WRQoL or MBI-GS and WRQoL) in both English and Malay versions. Therefore, each participant spent approximately 60 minutes to review, comment and complete a total of 4 sets of questionnaire. Each focus group was chaired by a moderator and the participants' feedback on the translated instruments were documented accordingly (Agency for Healthcare Research and Quality, 2012).

\subsection{Statistical Analysis}

Cohen's Kappa was a measurement of concordance or agreement between two methods of measurement. This method was applicable to both skewed and normally distributed data (Unknown, 2012a). It was further described by Cohen that the weighted kappa, which took the distance from agreement into consideration, was more appropriate for a variable with more than two possible outcomes (binary) (Cohen, 1968). Therefore, a weighted kappa was used to measure the strength of agreement between the English and Malay instruments. The specific weights used was $[1-\mid \mathrm{i}-\mathrm{j} /(\mathrm{k}-1)]$, where $\mathrm{i}$ and $\mathrm{j}$ index the rows and columns of the outcomes by the two instruments while $\mathrm{k}$ is the maximum number of possible outcomes (Unknown, 2012b).

An instrument cannot be considered valid unless it was reliable but not otherwise (Tavakol \& Dennick, 2011). Therefore, the Cronbach's alpha was used to assess the internal reliability of the translated instruments (Chen, 2009). By convention, a Cronbach's alpha value of at least 0.70 was highly desirable (Cronbach, 1951; Scientific Advisory Committee of the Medical Outcomes Trust, 2002).

The analyses were performed using STATA software version 11.0. All missing data were excluded from analyses.

\section{Results}

\subsection{Response Rate}

The response rate was $100 \%$ for Malay MBI-HSS, MBI-ES and MBI-GS, but only $97 \%$ response rate was reported for Malay WRQoL.

\subsection{Measurement of Agreement}

Table 1. Kappa value between English and Malay versions of MBI-HSS, MBI-ES, MBI-GS and WRQoL

\begin{tabular}{lllll}
\hline Item No. & $\begin{array}{l}\text { Malay } \\
\text { MBI - HSS }\end{array}$ & $\begin{array}{l}\text { Malay } \\
\text { MBI }- \text { ES }\end{array}$ & $\begin{array}{l}\text { Malay } \\
\text { MBI - GS }\end{array}$ & $\begin{array}{l}\text { Malay } \\
\text { WRQoL }\end{array}$ \\
\hline 1 & 0.7436 & 0.8462 & 0.9554 & 0.9416 \\
\hline 2 & 0.7647 & 0.9167 & 0.8095 & 0.7979 \\
\hline 3 & 1.0000 & 0.9324 & 0.9550 & 0.8528 \\
\hline 4 & 0.7468 & 0.8958 & 1.0000 & 0.4858 \\
\hline 5 & 0.8571 & 0.8649 & 0.8113 & 0.8612 \\
\hline 6 & 0.5968 & 1.0000 & 0.7368 & 0.9277 \\
\hline 7 & 0.3443 & 0.9107 & 1.0000 & 0.6873 \\
\hline 8 & 0.7945 & 0.8630 & 0.8276 & 0.8208 \\
\hline 9 & 0.8182 & 1.0000 & 0.8246 & 0.8685 \\
\hline 10 & 0.8148 & 0.8276 & 0.8684 & 0.7775 \\
\hline 11 & 0.5833 & 0.9091 & 0.5833 & 0.8123 \\
\hline 12 & 0.5161 & 0.6835 & 0.5833 & 0.8225 \\
\hline 13 & 0.7273 & 0.9342 & 0.7887 & 0.8147 \\
\hline
\end{tabular}




\begin{tabular}{|c|c|c|c|c|}
\hline Item No. & $\begin{array}{l}\text { Malay } \\
\text { MBI - HSS }\end{array}$ & $\begin{array}{l}\text { Malay } \\
\text { MBI - ES }\end{array}$ & $\begin{array}{l}\text { Malay } \\
\text { MBI - GS }\end{array}$ & $\begin{array}{l}\text { Malay } \\
\text { WRQoL }\end{array}$ \\
\hline 14 & 0.7778 & 0.8810 & 0.7436 & 0.8432 \\
\hline 15 & 0.8485 & 1.0000 & 0.6386 & 0.8088 \\
\hline 16 & 0.9057 & 0.9425 & 1.0000 & 0.6530 \\
\hline 17 & 0.3243 & 0.4068 & 8888 & 0.7487 \\
\hline 18 & 0.6032 & 0.5000 & 8 & 0.7797 \\
\hline 19 & 0.5238 & 0.9020 & 808 & 0.6744 \\
\hline 20 & 0.7656 & 0.8810 & 68 & 0.7623 \\
\hline 21 & 0.7945 & 0.9057 & 6 & 0.8546 \\
\hline 22 & 0.9153 & 0.8611 & 3 & 0.7839 \\
\hline 23 & \multirow{2}{*}{\multicolumn{3}{|c|}{ 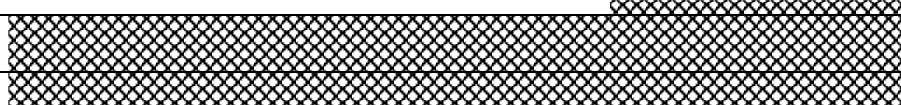 }} & 0.8114 \\
\hline 24 & & & & 0.6145 \\
\hline
\end{tabular}

As shown in Table 1, a moderate to almost perfect strength of agreement between the English and Malay versions of instruments was observed in this study. The Cohen kappa value ranged specifically from 0.3443 to 1.0000 for MBI-HSS, from 0.5000 to 1.0000 for MBI-ES, from 0.5833 to 1.0000 for MBI-GS and from 0.4858 to 0.9416 for WRQoL.

\subsection{Internal Reliability}

Table 2. Cronbach's alpha for the Malay versions of MBI-HSS, MBI-ES, MBI-GS and WRQoL

\begin{tabular}{|c|c|c|c|}
\hline Instruments & Sample size & Subscales & Cronbach's Alpha \\
\hline \multirow[t]{4}{*}{ Malay MBI - HSS } & \multirow[t]{4}{*}{10} & Overall & 0.9411 \\
\hline & & Emotional Exhaustion & 0.9558 \\
\hline & & Depersonalization & 0.9425 \\
\hline & & Personal Accomplishment & 0.8330 \\
\hline \multirow[t]{4}{*}{ Malay MBI - ES } & \multirow[t]{4}{*}{10} & Overall & 0.9170 \\
\hline & & Emotional Exhaustion & 0.9735 \\
\hline & & Depersonalization & 0.7474 \\
\hline & & Personal Accomplishment & 0.5620 \\
\hline \multirow[t]{4}{*}{ Malay MBI - GS } & \multirow[t]{4}{*}{10} & Overall & 0.9129 \\
\hline & & Professional Efficacy & 0,8480 \\
\hline & & Exhaustion & 0.9097 \\
\hline & & Cynicism & 0.7860 \\
\hline \multirow[t]{7}{*}{ Malay WRQoL } & \multirow[t]{7}{*}{29} & Overall & 0.9002 \\
\hline & & General Well-being & 0.8575 \\
\hline & & Home-work Interface & 0.8195 \\
\hline & & Job-Career Satisfaction & 0.6413 \\
\hline & & Control at Work & 0.5516 \\
\hline & & Working Conditions & 0.4038 \\
\hline & & Stress at Work & 0.6608 \\
\hline
\end{tabular}


Table 2 summarized the Cronbach's alpha for the translated instruments. Specifically, the overall Cronbach's alpha was at least 0.90 for Malay versions of MBI-HSS, MBI-ES, MBI-GS and WRQoL. This clearly indicated the items measured the same concept or construct (Tavakol \& Dennick, 2011). The Cronbach's alpha for subscales ranged from 0.8330 to 0.9558 for MBI-HSS, from 0.5620 to 0.9735 for MBI-ES, from 0.7860 to 0.9097 for MBI-GS and from 0.4038 to 0.8575 for WRQoL.

\section{Discussion}

This study stressed the importance in establishing equivalence when translating an instrument to ensure reliability of the translated instrument. This was done by studying the strength of agreement between the English and Malay versions of the instruments as well as the internal reliability of the translated instruments. It was also equally important to incorporate the language barriers, different cultural meanings of a cultural construct and varied interpretations in the translated instruments (Guillemin, Bombardier \& Beaton, 1993). A translated instrument with low cultural validity was most likely to be impractical (Hyrkas, Appelqvist-Schmidlechner \& Oksa, 2003).

There were 2 items (9\%) in MBI-HSS possessed kappa value of less than 0.4, which indicated only fair agreement between the English and Malay instruments. This was potentially due to different wording used, which could lead to slightly different perception of certain meanings of the words in the Malaysian context. No such concern was noted in the Malay versions of MBI-ES, MBI-GS and WRQoL.

The overall Cronbach's alpha for the Malay versions of MBI-HSS, MBI-ES, and MBI-GS was at least 0.90, which was well above the desirable value. This further confirmed that the items in each translated instruments were measuring the same concept or construct. Unfortunately, the Cronbach's alpha value for 4 out of 6 subscales in WRQoL was just slightly below the desirable value. This could potentially be affected by low number of items in such subscales (Tavakol \& Dennick, 2011).

Limitations were noted in this study. Firstly, some participants misunderstood the meanings of some items in the instruments and they did not feel comfortable to clarify the questions in front of other participants. Secondly, tight time schedule could have rushed the participants in answering the questionnaires. Thirdly, the pretest was conducted based on participants from the Klang Valley area which was an urban area, therefore, the authors were concerned whether the findings from this study can be generalized to participants from rural areas.

In conclusion, good strength of agreement was observed between English and Malay versions of MBI-HSS, MBI-ES, MBI-GS and WRQoL. In addition, desirable Cronbach's alpha was achieved for the Malay versions of MBI-HSS, MBI-ES, MBI-GS and WRQoL This study concluded that the Malay versions of MBI-HSS, MBI-ES, MBI-GS and WRQoL were culturally appropriate to be used in Malaysia. Further study involving a larger sample will be needed to further examine the psychometric properties of the translated instruments in Malaysia.

\section{Acknowledgements}

The authors also would like to thank Mind Garden, Inc. and Quality of Working Life for the permission to use the English MBI and WRQoL scale respectively. This project was approved by the Medical Research Ethics Committee, Ministry of Health Malaysia and SEGi University Ethics Committee. It was fully funded by an Exploratory Research Grant Scheme (ERGS/1/2011/SS/SEGI/03/1) from the Ministry of Higher Education Malaysia.

\section{References}

Agency for Healthcare Research and Quality. (2012). Translation Guidelines for the Surveys on Patient Safety Culture. U.S. Department of Health \& Human Services website. Retrieved from http://www.ahrq.gov/qual/patientsafetyculture/transguide.htm\#step6

Behling, O., \& Law, K. S. (2000). Translating questionnaires and other research instruments: Problems and solutions. Thousand Oaks, CA: Sage Publications Inc.

Center for Aging in Diverse Communities. (2010). Guidelines for translating surveys in cross-cultural research. University of California San Francisco website. Retrieved from http://dgim.ucsf.edu/cadc/cores/measurement/translationguide.pdf

Chen W. S. (2009). Questionnaire translation and psychometric properties evaluation. SEGi Review, 2(2), 62-71.

Cohen, J. (1968). Weighted kappa: nominal scale agreement with provision for scale and disagreement or partial credit. Psychol Bull, 70, 213-220. http://dx.doi.org/10.1037/h0026256 
Cronbach, L. F. (1951). Coefficient alpha and the internal structure of tests. Psychometricka, 16, 297-334. http://dx.doi.org/10.1007/BF02310555

Easton, S. A., \& Van Laar, D. L. (2012). User Manual for the Work-Related Quality of Life (WRQoL) Scale: A Measure of Quality of Working Life. United Kingdom: University of Portsmouth

Edelwich, J., \& Brodsky, A. (1980). Burnout: stages of disillusionment in the helping professions. New York: Human science press.

Freudenberger, H. J. (1974). Staff burnout. Journal of social issues, 30, 159-65.

Glozier, N. (2002). Mental ill health and fitness for work. Journal of occupational and environmental medicine, 59, 714-720. http://dx.doi.org/10.1136/oem.59.10.714

Guillemin, F., Bombardier, C., \& Beaton, D. (1993). Cross-cultural adaptation of health related quality of life measures: literature review and proposed guidelines. Journal of Clinical Epidemiology, 46, 1417-1432. http://dx.doi.org/10.1016/0895-4356(93)90142-N

Hyrkas, K., Appelqvist-Schmidlechner, K., \& Oksa, L. (2003). Validating an instrument for clinical supervision using an expert panel. International Journal of Nursing Studies, 40, 619-625. http://dx.doi.org/10.1016/S0020-7489(03)00036-1

Kraft, U. (2006). Burned out: your job is extremely fulfilling. It is also extremely demanding - And you feel overwhelmed. You are not alone. Scientific American Mind, June/July 2006, page 29-33.

Leiter, M. P., \& Maslach, C. (2005a). Banishing Burnout: Six strategies for improving your relationship with work. San Francisco, CA: Jossey-Bass.

Leiter, M. P., \& Maslach, C. (2005b). A mediation model of job burnout. In Antoniou, A. S., \& Cooper, C. L. (Eds.) Research companion to organizational health psychology (pp. 544-564). Cheltenham, United Kingdom: Elgar Publishing.

Maslach, C. (2003). Job burnout: New directions in research and intervention. Current Directions in Psychological Science, 12, 189-192. http://dx.doi.org/10.1111/1467-8721.01258

Maslach, C., \& Leiter, M. P. (1997). The Truth About Burnout: How organizations cause personal stress and what to do about it. San Francisco, CA: Jossey-Bass.

Maslach, C., \& Leiter, M. P. (2008). Early predictors of job burnout and engagement. Journal of Applied Psychology, 93, 498-512. http://dx.doi.org/10.1037/0021-9010.93.3.498

Maslach, C., Jackson, S. E., \& Leiter, M. P. (1996). Maslach Burnout Inventory Manual (3rd ed.). Menlo Park, CA: Mind Garden.

Maslach, C., Leiter, M. P., \& Schaufeli, W. B. (2009). Measuring burnout. In S. Cartwright \& C. L. Cooper (Eds.) The Oxford handbook of organizational well-being (pp. 86-108). Oxford, United Kingdom: Oxford University Press.

Pines, A., \& Aronson, E. (1981). From tedium to personal growth. New York: Free press.

Quality of Working Life (QoWL). (2012). The Work-Related Quality of Life (WRQoL) Scale. Retrieved from http://www.qowl.co.uk/qowl_wrqol_scale.html

Sarros, J. C., \& Densten, I. L. (1989). Undergraduate students stress and coping strategies. Higher education research and development, 8, 47-57. http://dx.doi.org/10.1080/0729436890080105

Scientific Advisory Committee of the Medical Outcomes Trust. (2002). Assessing health status and quality of life instruments: Attributes and review criteria. Qual Life Res, 11, 193-205.

Tavakol, M., \& Dennick, R. (2011). Making sense of Cronbach's alpha. International Journal of Medical Education, 2, 53-55.

Unknown. (2012a). Cohen's and Fleiss's Kappa Introduction and Explanation. Stattools.net website. Retrieved from http://www.stattools.net/CohenKappa_Exp.php

Unknown. (2012b). Stata 12 help for kappa. Stata website. Retrieved from http://www.stata.com/help.cgi?kappa

World Health Organization (WHO). (1994). ICD-10: International classification of diseases. Geneva.

4-Life Psychology Centre. (2012). What is burnout? 4Life Psychology Centre website. Retrieved from http://www.4-life.com.au/pdf/tip_burnout.pdf 